\title{
Mid-ocean microseisms
}

\author{
Peter D. Bromirski \\ Integrative Oceanography Division, Scripps Institution of Oceanography, University of California, San Diego, 9500 \\ Gilman Drive, La Jolla, California 92093-0209, USA (pbromirski@ucsd.edu)
}

\section{Fred K. Duennebier}

Department of Geology and Geophysics, School of Ocean and Earth Sciences and Technology, University of Harwaii, Honolulu, Hawaii 96822, USA (fkd@hawaii.edu)

\section{Ralph A. Stephen \\ Woods Hole Oceanographic Institution, MS24, Woods Hole, Massachusetts 02543-1542, USA (rstephen@whoi.edu)}

[1] The Hawaii-2 Observatory (H2O) is an excellent site for studying the source regions and propagation of microseisms since it is located far from shorelines and shallow water. During Leg 200 of the Ocean Drilling Program, the officers of the JOIDES Resolution took wind and wave measurements for comparison with double-frequency (DF) microseism data collected at nearby $\mathrm{H} 2 \mathrm{O}$. The DF microseism band can be divided into short-period and long-period bands, SPDF and LPDF, respectively. Comparison of the ship's weather log with the seismic data in the SPDF band from about 0.20 to $0.45 \mathrm{~Hz}$ shows a strong correlation of seismic amplitude with wind speed and direction, implying that the energy reaching the ocean floor is generated locally by ocean gravity waves. Nearshore land seismic stations see similar SPDF spectra, also generated locally by wind seas. At H2O, SPDF microseism amplitudes lag sustained changes in wind speed and direction by several hours, with the lag increasing with wave period. This lag may be associated with the time necessary for the development of opposing seas for DF microseism generation. Correlation of swell height above H2O with the LPDF band from 0.085 to $0.20 \mathrm{~Hz}$ is often poor, implying that a significant portion of this energy originates at distant locations. Correlation of the $\mathrm{H} 2 \mathrm{O}$ seismic data with NOAA buoy data, with hindcast wave height data from the North Pacific, and with seismic data from mainland and island stations, defines likely source areas of the LPDF signals. Most of the LPDF energy at $\mathrm{H} 2 \mathrm{O}$ appears to be generated by high-amplitude storm waves impacting long stretches of coastline nearly simultaneously, and the Hawaiian Islands appear to be a significant source of LPDF energy in the North Pacific when waves arrive from particular directions. The highest levels observed at mid-ocean site H2O occur in the SPDF band when two coincident nearby storm systems develop. Deep water, mid-ocean-generated DF microseisms are not observed at continental sites, indicating high attenuation of these signals. At near-coastal seismic stations, both SPDF and LPDF microseism levels are generally dominated by local generation at nearby shorelines.

Components: 8603 words, 13 figures, 1 animation.

Keywords: Microseisms; ocean gravity waves; seismic noise; Rayleigh wave attenuation; oceanic Q; Hawaii-2 Observatory.

Index Terms: 7299 Seismology: General or miscellaneous; 4299 Oceanography: General: General or miscellaneous; 4560 Oceanography: Physical: Surface waves and tides (1222); 3099 Marine Geology and Geophysics: General or miscellaneous.

Received 4 June 2004; Revised 10 January 2005; Accepted 17 February 2005; Published 20 April 2005.

Bromirski, P. D., F. K. Duennebier, and R. A. Stephen (2005), Mid-ocean microseisms, Geochem. Geophys. Geosyst., 6, Q04009, doi:10.1029/2004GC000768. 


\section{Introduction}

[2] High levels of seismic noise in the frequency band from 0.05 to about $2 \mathrm{~Hz}$ are observed world wide, with lower levels at land stations far from the ocean [Bromirski, 2001]. The peak in this portion of the seismic noise spectrum, called the microseism peak, is caused by ocean wave energy coupling into motion of the earth. Two types of microseisms are observed at seismic stations, primary and secondary microseisms. Primary microseisms are generated by direct ocean wave pressure fluctuations at the ocean bottom and have the same frequency as the ocean waves that generate them. The amplitude of waveinduced pressure fluctuations decreases exponentially with depth from the ocean surface [see, e.g., Bromirski and Duennebier, 2002]; thus significant primary microseisms are only generated in shallow water where the water depth is less than half the wavelength of wind-forced gravity waves, and thus are not generated in the open ocean far from land. Primary microseisms generated nearshore have been observed in relatively nearby deep water [Stephen et al., 2003b; Sutton and Barstow, 1990].

[3] Secondary microseisms are observed at twice the frequency of the ocean waves and thus are termed double-frequency, or DF, microseisms. The origin of DF microseisms has been explained by the theory of Longuet-Higgins [1950] and others [e.g., Hasselmann, 1963; Kibblewhite and Wu, 1991]. The mechanism requires the interaction of opposing wave fields having nearly the same wave number, generating a pressure excitation pulse at twice the wave frequency that propagates nearly unattenuated to the ocean floor where it is converted to microseism energy. In the coastal regions of islands and continents, opposing gravity wave energy in the band between about 0.04 and $0.10 \mathrm{~Hz}$ (25 to $10 \mathrm{~s}$ period) is thought to result primarily from waves reflected and/or scattered from irregular shorelines interacting with incident wave energy, as indicated by the high correlation of local wave height with microseism amplitudes [Kibblewhite and Ewans, 1985; Bromirski et al., 1999]. Many papers have dealt with identifying the source regions of microseisms observed at seismic stations on land [Cessaro, 1994; Friedrich et al., 1998; Bromirski, 2001; Bromirski and Duennebier, 2002; Essen et al., 2003], with the general conclusion that microseism energy is coupled into the crust near shorelines from wave activity, and is radiated as Rayleigh waves. Some shorelines appear to generate more microseism energy than others [Cessaro, 1994; Bromirski, 2001].
[4] Microseisms are also observed at seismic stations at and below the ocean floor [Sutton and Barstow, 1990; Kibblewhite and Wu, 1993; Bradley et al., 1997; Webb, 1998; Stephen et al., 2003b]. Dorman et al. [1993] distinguished between DF microseisms generated by swell from distant storms and those generated by waves induced by local winds (at the lower and upper ends of the 0.10 to $5 \mathrm{~Hz}$ band, respectively). This often results in the splitting of the DF microseism peak into two peaks [see Stephen et al., 2003b, Figure 18], at about $0.085-0.20 \mathrm{~Hz}$ and $0.20-$ $0.5 \mathrm{~Hz}$, which we refer to in this paper as longperiod DF (LPDF) and short-period DF (SPDF) microseisms. The limiting microseism spectrum between about 0.5 and $5 \mathrm{~Hz}$ observed by hydrophones on the ocean floor was termed the Holu spectrum by McCreery et al. [1993]. Once excited, the microseism noise propagates through the oceanic crust as Stoneley/Rayleigh modes [Haubrich and McCamy, 1969], so the characteristics of the spectra will depend on the shear wave velocities and attenuation of the sediments and crust [Schreiner and Dorman, 1990; Dorman et al., 1991]. Shear wave resonances in the sediments create peaks in the Holu spectrum observed by seismic sensors, and also at SPDF frequencies [Stephen et al., 2003b]. Depending on sediment thickness and rigidity, these resonances cause sharp spectral peaks that can make the SPDF peak appear narrower and higher in amplitude than would be observed in the absence of the sediments (e.g., in a borehole in basaltic basement). Nonetheless, ocean bottom acoustic noise spectra can act as a proxy for short-period ocean wave amplitude spectra, and thus wind speed.

[5] In this paper we focus on LPDF and SPDF microseisms. Several questions concerning the origin and propagation of these microseisms are addressed in this paper: (1) Can storms at sea far from land generate both LPDF and SPDF microseisms that are observed at distant seismic stations? (2) How far do SPDF microseisms at frequencies above $0.20 \mathrm{~Hz}$ propagate across the ocean floor? (3) Are SPDF and LPDF microseisms generated near distant shorelines observed at mid-ocean seafloor stations?

[6] The principal data used in this study were collected at the Hawaii-2 Observatory (H2O), located roughly halfway between Hawaii and California at $4977 \mathrm{~m}$ depth, more than $1,500 \mathrm{~km}$ from the nearest coastline. The location of this station is unique for microseism studies since its distance 
from shorelines allows coastal and open ocean microseism generation to be distinguished. Microseisms generated by large waves hitting distant shorelines should not correlate well with microseisms generated by local waves.

[7] The data used in many microseism papers are either from land seismic stations or ocean bottom stations relatively close to shore. Because the ocean wave spectrum is effectively the same above nearcoastal ocean bottom seismometers and at the closest shorelines, it is often difficult to tell whether the observed DF microseism energy came from Rayleigh waves generated by interaction of waves near shorelines or whether the energy came from wavewave interactions directly above ocean bottom stations [e.g., Babcock et al., 1994]. Also, while there is no question that high waves impacting shorelines generate DF microseisms, it remains unclear what portion of the microseism spectrum observed on land is generated by wave-wave interactions in the open ocean far from land. This question is addressed by Cessaro [1994], but his results, suggesting that DF microseisms are generated in the open ocean under storms, are contradicted by data presented by Bromirski and Duennebier [2002]. To address this question, we requested that the JOIDES Resolution officers make wind and sea observations during their time on station above the Hawaii-2 Observatory from 26 December 2001 until 24 January 2002. These data could then be correlated with signals recorded at the observatory below and at distant seismic stations.

[8] The $\mathrm{H} 2 \mathrm{O}$ data also address the question of how far DF microseisms propagate across the ocean. As storms approach the Hawaii-2 Observatory, the noise level at the ocean floor should increase before the storm and the storm waves arrive if microseisms are being generated at the site of the storm. If the DF microseism energy generated by wind seas does not propagate an appreciable distance, then the microseisms should reflect the wave and wind conditions at the surface near the observatory.

[9] The $\mathrm{H} 2 \mathrm{O}$ data are examined to determine if the DF microseisms observed at $\mathrm{H} 2 \mathrm{O}$ correlate with DF microseisms observed at distant land stations. We also look at the North Pacific wave climate during that time to determine whether peaks in the microseism spectrum coincide with the arrival of high-amplitude waves at shorelines or with high waves under storms in the open ocean.

[10] Primary microseisms are far less energetic than DF microseisms. Propagation losses from shallow water generation areas to $\mathrm{H} 2 \mathrm{O}$ generally reduce primary microseism amplitudes to near or below the noise floor at $\mathrm{H} 2 \mathrm{O}$ in the $[0.04,0.085]$ $\mathrm{Hz}$ band. Consequently, primary microseism variability is not considered in this study. However, the coincident observation of primary and associated DF microseisms is an important indicator of nearcoastal DF generation.

\section{Data}

[11] The $\mathrm{H} 2 \mathrm{O}$ seismic system contains orthogonal Guralp CMG-3 seismometers buried about $0.5 \mathrm{~m}$ below the ocean floor [Duennebier et al., 2002]. A hydrophone sensitive to frequencies from 0.01 to $80 \mathrm{~Hz}$, and short-period seismic sensors were also recorded. The data were transmitted in real-time over the Hawaii-2 cable to Oahu, Hawaii, where they were reformatted into SEED format and transmitted to the IRIS Data Management Center in Seattle, Washington, where they are publicly available. Additional seismic data were obtained from IRIS for seismic stations in Hawaii and on the West Coast, and from Northern California Earthquake Data Center (NCEDC) stations in California (Figure 1). In this study we use data decimated to 1 sample/sec.

[12] Spectral data are presented in two forms, spectrograms with power spectral density (PSD) contoured as a function of frequency versus time, and difference spectrograms where the PSD is divided by the mean (the mean is subtracted in $\mathrm{dB}$ space). Removing the mean spectral amplitude at each frequency emphasizes relative temporal changes while discarding absolute amplitudes and the effects of stationary system and environmental responses. An example of each type of plot for the same data is shown in Figure 2. Data were processed using Welch averaging of 1024 sample segments with a 512 sample (about $8.5 \mathrm{~min}$ ) FFT length and a 256 sample overlap. The resulting spectra were then smoothed with a nine point moving average.

[13] Hourly averaged horizontal component acceleration spectra (Figure 2, top) indicate that the midocean microseism peak is generally between 0.2 and $0.3 \mathrm{~Hz}$, with SPDF amplitudes often much higher than LPDF levels. The lower end of the LPDF band varies from about 0.085 to $0.12 \mathrm{~Hz}$, with a sharp drop in energy below about $0.085 \mathrm{~Hz}$. Several different spectral regions are visible in the difference spectrogram at $\mathrm{H} 2 \mathrm{O}$ (Figure 2, bottom). At frequencies below $0.05 \mathrm{~Hz}$, the horizontal 


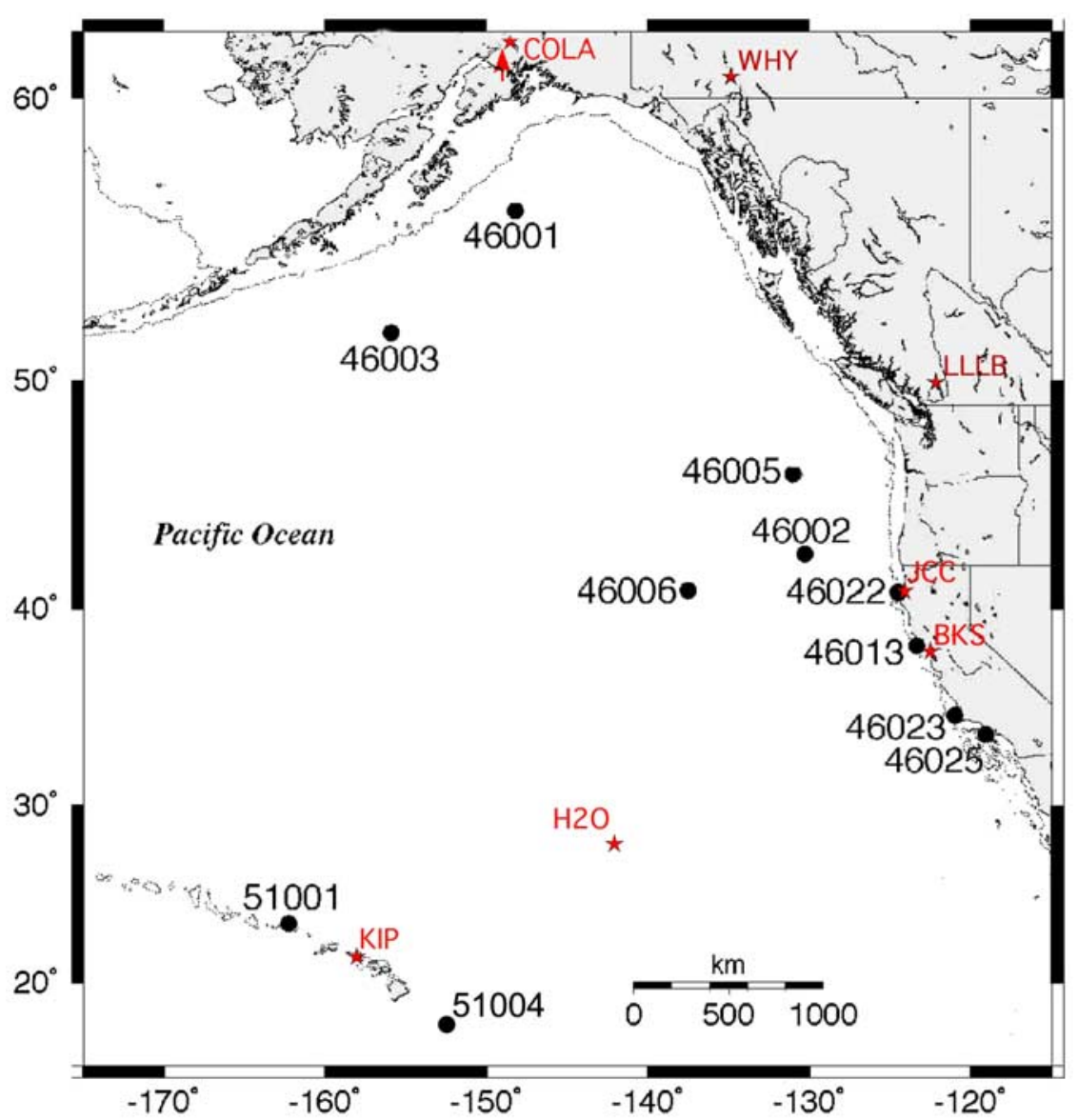

Figure 1. Seismic stations and NOAA buoys whose data were examined as part of this study.

sensors respond to tidal currents, even though they are buried below the ocean floor, yielding the peaks at roughly 24 hour intervals. Background noise is relatively constant between about 0.04 and $0.085 \mathrm{~Hz}$, except when energy from distant earthquakes is present. This is the band where primary microseism energy is observed. The LPDF microseism band is between about 0.085 and about $0.20 \mathrm{~Hz}$, and the SPDF microseism band is from $0.20-0.45 \mathrm{~Hz}$. Note that peaks in the LPDF band do not extend to frequencies higher than about $0.20 \mathrm{~Hz}$, and peaks in the SPDF band do not extend far below $0.20 \mathrm{~Hz}$. The Holu spectrum, from about $0.5-5 \mathrm{~Hz}$, which also results from wind-wave generated DF microseisms [McCreery et al., 1993], is not shown. The noise above $5 \mathrm{~Hz}$ has contributions from shipping and breaking waves.

[14] The officers on the JOIDES Resolution made wind, sea, and swell amplitude and direction observations at least once every four hours while the ship was on site near the Hawaii-2 Observatory from 16 December 2001 to 24
January 2002 [Stephen et al., 2003a]. Wave and wind data recorded by the JOIDES Resolution are shown in Figures 3 and 4. Wind data were obtained from instruments recorded on the bridge, while the sea and swell observations were visual, and are thus subjective. Because of the difficulty of visual estimation of amplitudes and directions of seas and swell when seas are high, we give less credibility to the wave observations made by the ship than to the wind measurements.

[15] To examine the wave climate, significant wave height $(\mathrm{Hs}$, the average of the highest $1 / 3$ of the waves) data were obtained for the various NOAA buoys in the NE Pacific shown in Figure 1. Archived Hs data can be found at the NDBC Web site (http://www.ndbc.noaa.gov/). Additionally, hindcast $\mathrm{Hs}$ data were used to generate a video, Animation 1, of the gravity wave field in the North Pacific produced using WAVEWATCH III [Tolman, 1999] with forcing provided by NCEP/ NCAR reanalysis winds. Animation 1 allows us to examine the synoptic variability of high-amplitude 

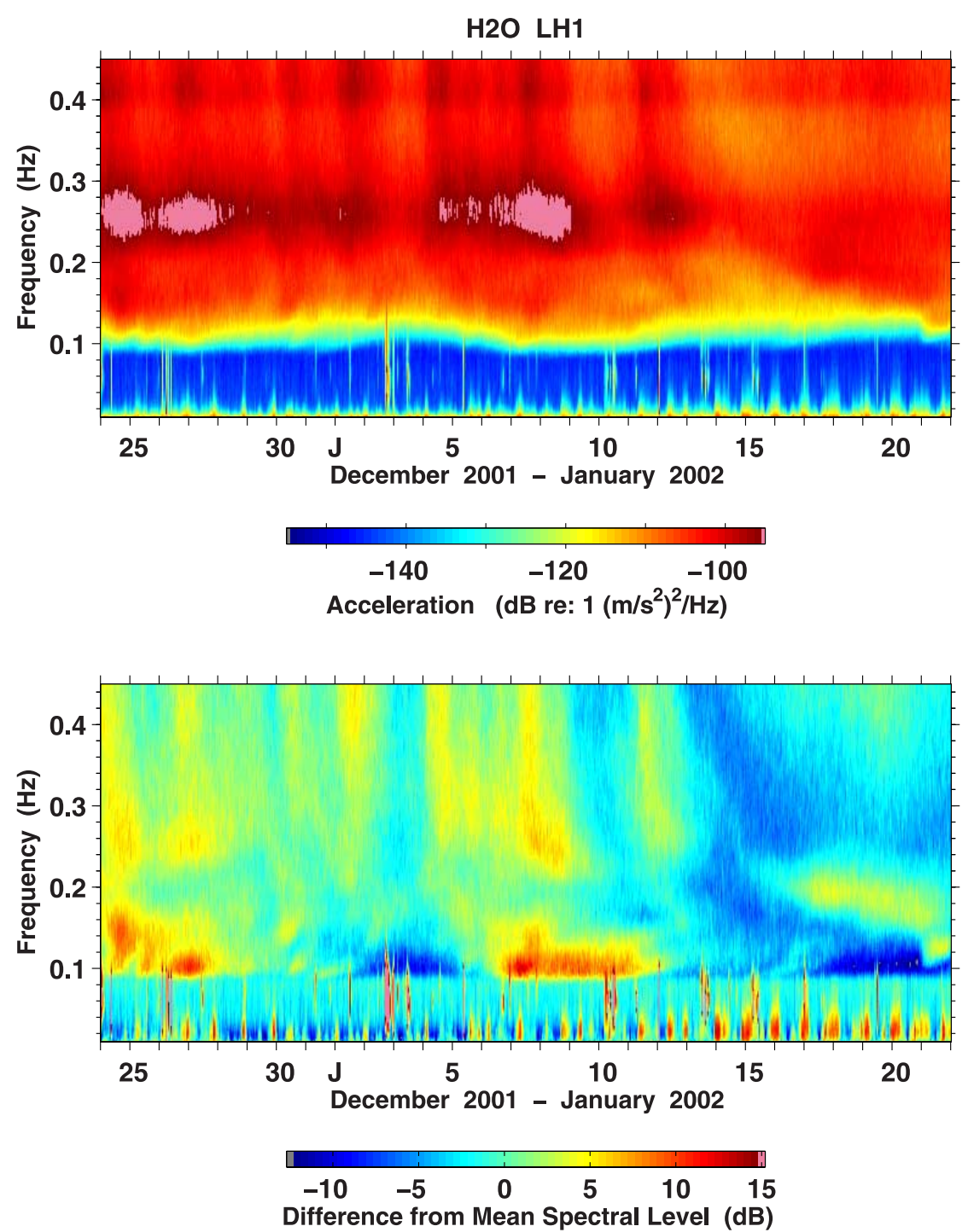

Figure 2. A spectrogram of horizontal component seismic data is shown on the top, and a difference spectrogram is shown at the bottom for the same data. By removing the mean level at each frequency during the time period shown, the difference spectrogram emphasizes temporal variations at the expense of losing absolute amplitudes.

waves in the North Pacific basin, and when they impact shorelines.

\section{SPDF Microseism Observations: Time Evolution}

[16] The difference spectrogram for the buried vertical seismometer at $\mathrm{H} 2 \mathrm{O}$ is shown in Figure 5, overlain by the average wind speed and direction data measured at the drill ship above. In general, higher wind speeds lead to higher SPDF (shortperiod double-frequency) microseism levels, as expected. The SPDF microseism levels remain relatively low for about 6-18 hours after wind speed (blue line) increases, generally rising sharply when the wind direction (green line) changes appreciably, with the lag presumably associated with the time necessary to develop opposing seas after the wind direction changes. Note that lower than expected SPDF microseism levels occur during times of relatively high wind speed when the wind direction is nearly constant, e.g., during 1621 January, indicating a lack of opposing wave components.

[17] The high correlation of the combinaton of increased wind speed and changes in wind direction with the SPDF levels indicates that SPDF microseism energy is not propagating a significant distance along the ocean floor; otherwise, the microseism levels would increase before the wind 
Joides Resolution Ship Log Leg 200: Seas \& Swell
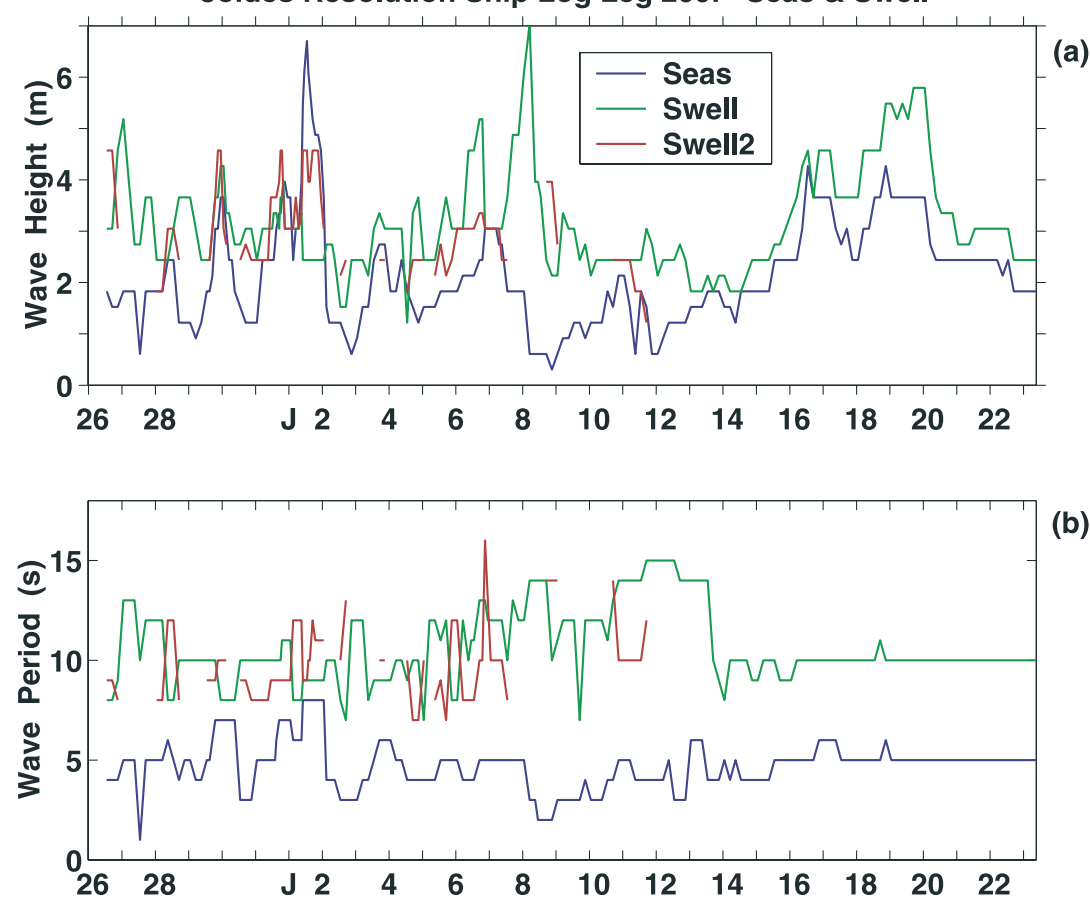

(b)

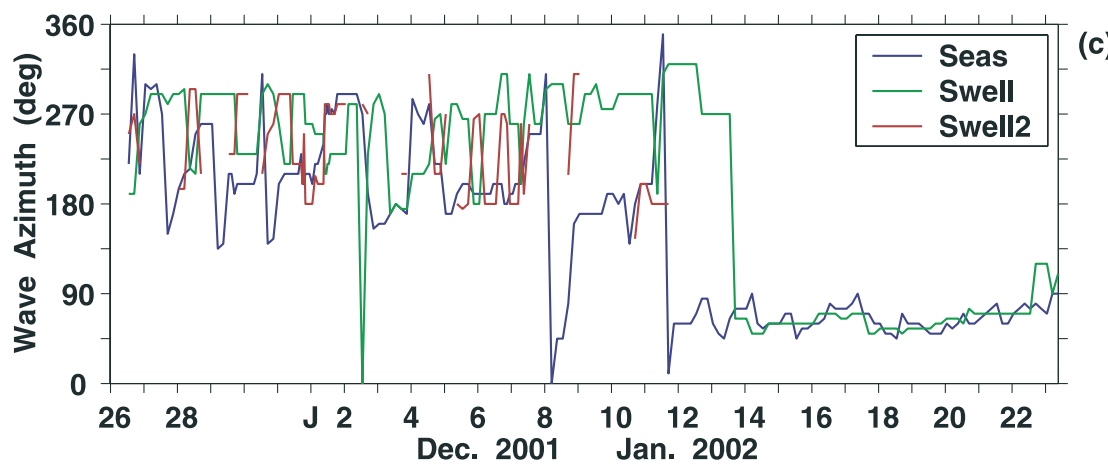

Figure 3. Visual wave observations composed of locally generated wind seas (SEAS) and swell (the dominant SWELL and occasionally identified secondary SWELL2) recorded by the officers of the JOIDES Resolution while at the $\mathrm{H} 2 \mathrm{O}$ site.

increased and the direction changed. Because short-period gravity waves are forced at low wind speeds over small areas in short time spans by local shifting winds, we expect the wave directional spectrum to be generally more omnidirectional as wave period decreases. This results in elevated microseism levels at frequencies above about $0.20 \mathrm{~Hz}$ at open ocean sites when the wind is blowing. The SPDF microseism levels above $0.20 \mathrm{~Hz}$ do not correlate as well with wave observations from the bridge of the JOIDES Resolution as they do with wind speed. This is likely due to the difficulty in making accurate observations of wave height and direction, compared to measuring wind speed.
[18] The high correlation of local winds with microseisms stops at the break between SPDF and LPDF microseisms at about $0.20 \mathrm{~Hz}$ (e.g., the 1 January event), suggesting that below this frequency there generally appears to be a nonlocal source area for the microseism signal. SPDF microseism levels increase at higher frequencies first, with increases at lower frequencies delayed by the time required to generate wave amplitudes at longer periods as elevated wind speeds persist. We conclude that SPDF microseisms are produced nearby from local storm activity, with no measurable propagation in the horizontal direction. SPDF microseisms do not appear to propagate efficiently over large distances. 

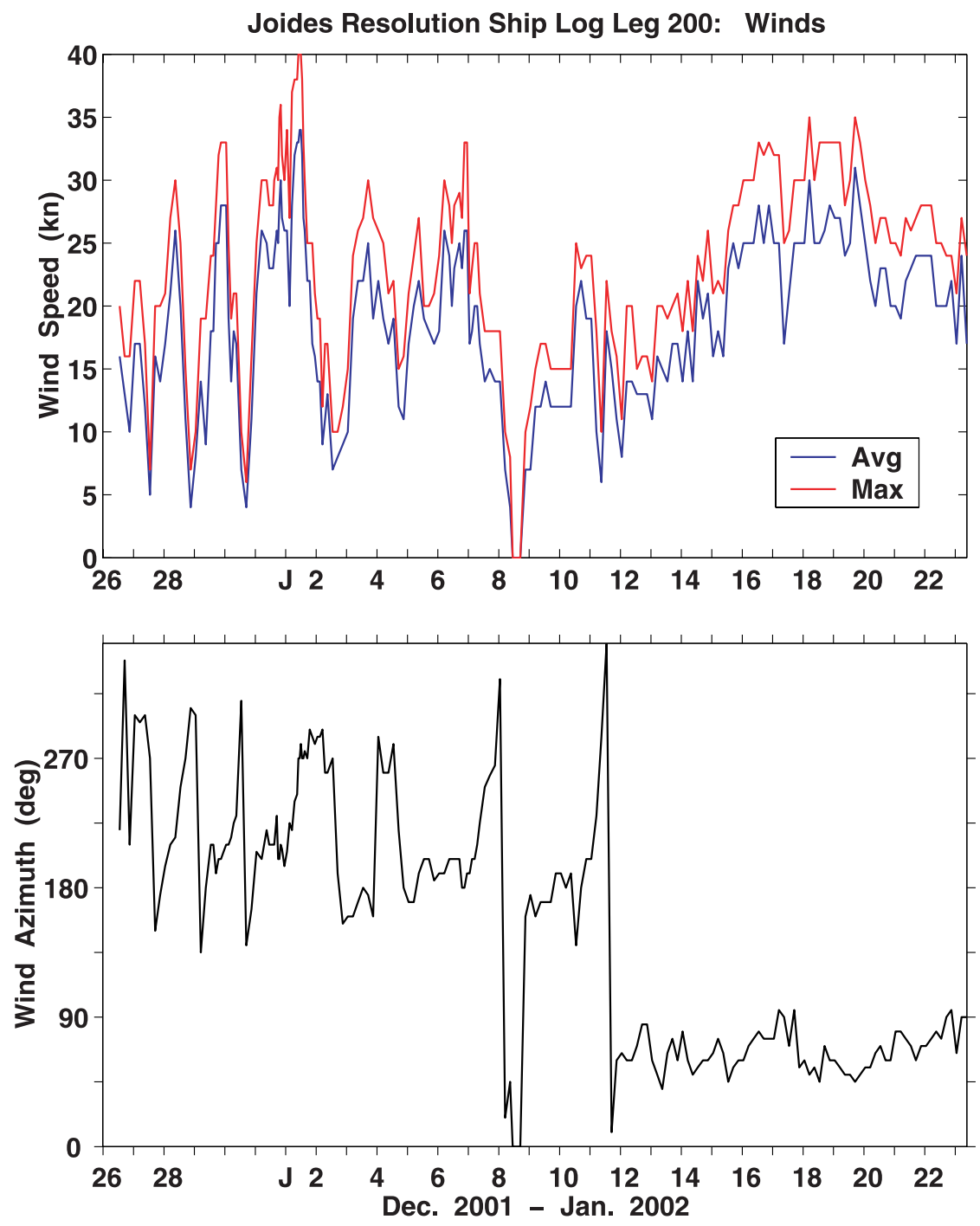

Figure 4. Wind data recorded by the JOIDES Resolution while at the Hawaii-2 Observatory.

[19] High relative SPDF levels observed at JCC during 14-15 December (Figure 6) are not observed at $\mathrm{H} 2 \mathrm{O}$ or KIP, and high levels observed at $\mathrm{H} 2 \mathrm{O}$ during 10-11 February (Figure 9) are not observed at JCC or KIP. The lack of correlation between SPDF levels over large distances indicates that SPDF microseisms do not propagate well from shorelines across ocean basins or from the deep ocean to shorelines, consistent with low effective Q. Because $\mathrm{H} 2 \mathrm{O}$ and KIP are often subject to the same storm systems nearly concurrently, differences between KIP and $\mathrm{H} 2 \mathrm{O}$ resulting from propagation effects are less clear.

[20] The time evolution of LPDF microseisms is opposite to SPDF microseisms and is similar to dispersed gravity wave trains, where low-frequency waves propagate faster than high frequencies.
An apparent exception to the usual LPDF time evolution occurs between 16 and 21 January 2002 (Figure 5), when the frequency of the peak microseism levels decreases from about 0.21 to $0.16 \mathrm{~Hz}$ over 5 days. During this time period there was a large storm over $\mathrm{H} 2 \mathrm{O}$, generating waves at periods longer than $10 \mathrm{~s}$. The presence of locally generated DF microseisms at less than $0.20 \mathrm{~Hz}$ indicates that there must have been some opposing swell present (Figure 2), which interacted with the growing seas as the storm evolved. Thus it is possible for large storms in the open ocean to generate high-frequency LPDF microseisms locally. The amplitude of the microseisms produced in these instances is much less than LPDFs observed at near-coastal seismic stations. As high-amplitude seas were observed over $\mathrm{H} 2 \mathrm{O}$ during this event (Figure 3), the relatively low microseism levels indicate that either the 


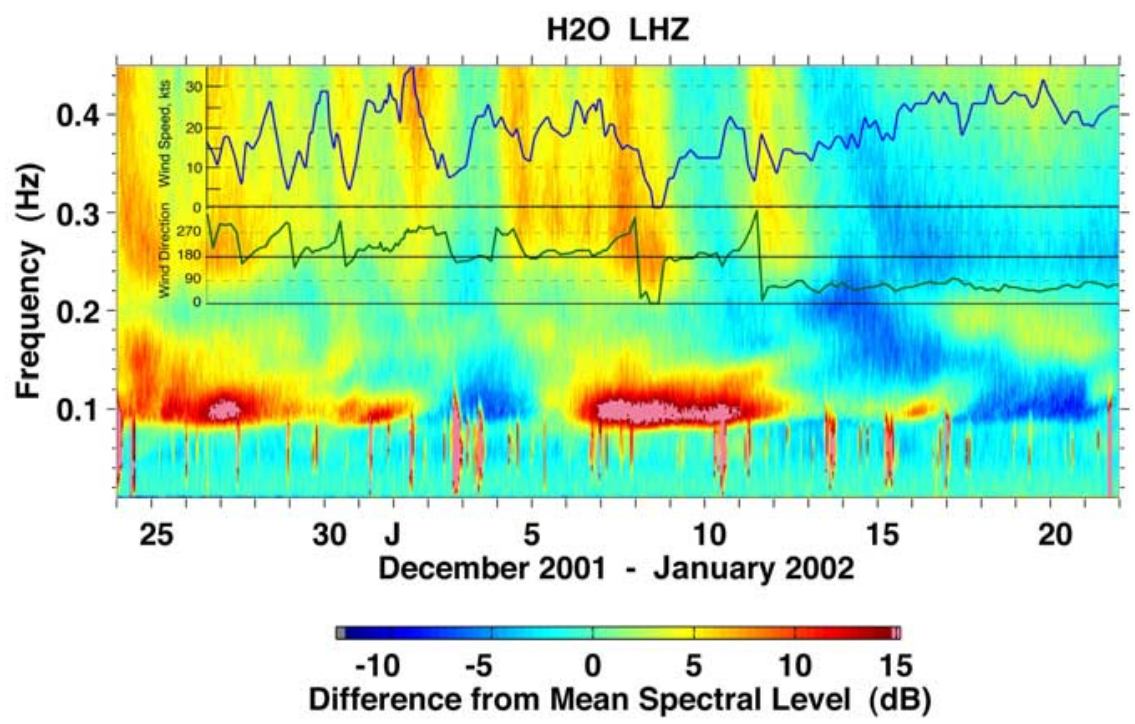

Figure 5. Correlation of local wind speed (blue line) and direction (green line) with seismic noise at $\mathrm{H} 2 \mathrm{O}$ recorded by the broadband vertical seismometer. The mean spectrum was obtained for the December 2001 to February 2002 time period, thus emphasizing the significance of the high-amplitude events compared with the horizontal sensor in Figure 2.

opposing wave energy and/or the effective area of wave-wave interactions were less than what generally occurs in near-coastal locations. Although some contribution to these signal levels from Hawaii generation is possible (see Animation 1), difference spectrograms indicate that these signals did not reach the California coast (Figure 6, JCC). Thus a large storm alone or a large swell alone will not generate high-amplitude DF microseisms in the open ocean that can be observed at continental stations.

\section{Comparison of LPDF Levels With Model Significant Wave Height}

[21] To determine likely source regions of the LPDF (long-period double-frequency) microseism signals, seismic noise levels were compared with model significant wave height (Hs) data across the North Pacific. Gravity wave amplitude and period depends on wind speed, fetch (the area over which the winds are acting), and the duration that winds persist. The ocean wave spectrum saturates at high frequencies, reaching the frequency-dependent maximum amplitude when increased wind speed and fetch are maintained. Thus storm intensity can be estimated in the wave model data from a combination of a storm's peak Hs, spatial extent, and duration, with storm tracks associated with the temporal evolution of the Hs surface. The model Hs data, Animation 1, shows that gravity waves generated by storms moving from west to east in the North Pacific resulted in the major swells observed at $\mathrm{H} 2 \mathrm{O}$, except for the waves arriving about 20 January, which originate from a storm that developed near $\mathrm{H} 2 \mathrm{O}$ on 16 January, and then strengthened and moved west to Hawaii.

[22] The LPDF microseism signals recorded at the Hawaii-2 Observatory $(\mathrm{H} 2 \mathrm{O})$ correlate with signals at other seismic stations in the North Pacific (KIP, BKS, JCC, and COLA), clearly shown by comparing difference spectrograms (Figure 6; see Figure 1 for locations). The times of high-amplitude LPDF microseisms are strongly correlated over synoptic timescales (days), with the differences increasing as the correlation timescale becomes shorter. The relative amplitudes of peaks vary considerably from station to station, as expected, since the strength of an individual DF microseism peak will depend on the amplitudes of the opposing wave components in the generation region, the area of wave-wave interactions, and the distance from the generation area. Thus, because of seismic attenuation and spreading losses, extreme waves interacting over a small area will not necessarily generate LPDF microseisms that can be detected at large distances from the generation area. Comparison of relative amplitudes gives an indication of the source region, e.g., higher relative amplitudes at COLA and LLLB compared with JCC, H2O, and KIP implies a Pacific Northwest coastal source region.

[23] The times of low relative microseism energy correlate across the stations (Figure 6), indicating 

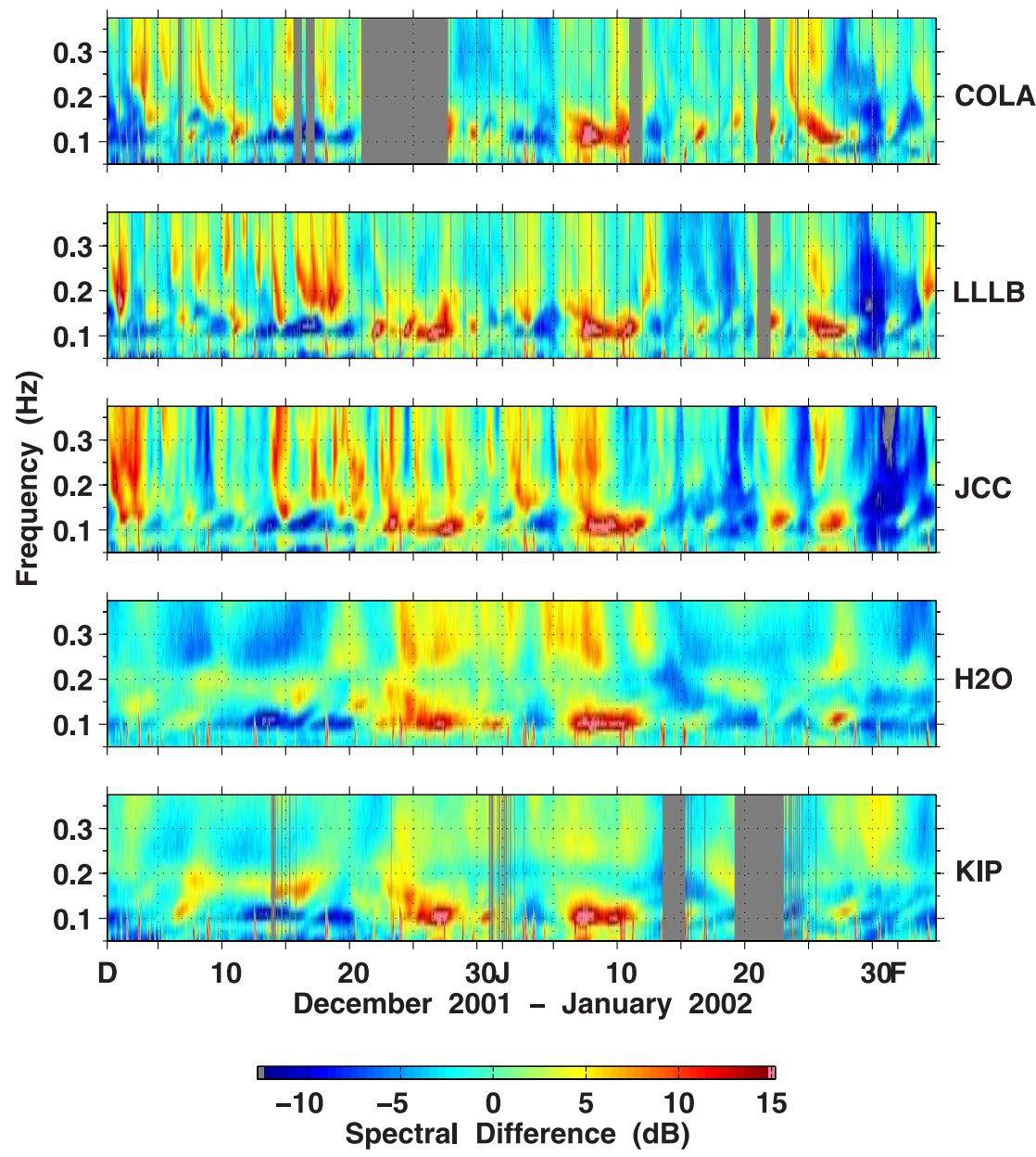

Figure 6. Difference spectrograms of vertical component data from eastern North Pacific seismic stations located in Hawaii (KIP), Alaska (COLA), Canada (LLLB), California (JCC), and mid-ocean H2O during December 2001 and January 2002, showing the similarity of energy in the LPDF microseism band (the mean spectrum subtracted was determined for the time period shown, resulting in slightly different levels observed compared with the vertical sensor data in Figure 5). Dark vertical strips indicate times when data are missing.

that there is little energy being coupled into LPDF microseisms anywhere in the North Pacific during these times. This observation is particularly important since a very large North Pacific storm was evolving from 3 January to 5 January 2002, when DF microseism levels are relatively low in the $[0.085,0.20] \mathrm{Hz}$ band. During this time period, the peak $\mathrm{Hs}$ north of $\mathrm{H} 2 \mathrm{O}$ was in excess of $10 \mathrm{~m}$, while the average $\mathrm{Hs}$ at $\mathrm{H} 2 \mathrm{O}$ was about $3 \mathrm{~m}$ (Figure 8, top), and the LPDF levels are not well correlated with model $\mathrm{Hs}$ at $\mathrm{H} 2 \mathrm{O}$. Comparison of Figure 6 with wave model Animation 1 shows that high LPDF microseism levels occurred at times when high waves were impacting shorelines over a wide area (Figure 8, bottom). Waves from the 310 January storm systems impact the Pacific Northwest from the Gulf of Alaska to San Francisco on 6 January, generating strong LPDF microseisms observed nearly simultaneously at all stations.
LPDF generation initially appears to occur at Hawaii (compare Figure 6 and Animation 1), with some LPDF generation possibly along the West Coast. Note that elevated LPDF levels are observed at $\mathrm{H} 2 \mathrm{O}$ on 9 January, when both model and observed $\mathrm{Hs}$ at $\mathrm{H} 2 \mathrm{O}$ are low, consistent with low correlation between LPDF levels and model Hs at $\mathrm{H} 2 \mathrm{O}$ near the end of 9 January (Figure 7).

[24] The higher relative LPDF levels during $7-$ 10 January than during 1-4 January underscores the importance of coastal gravity wave reflection to provide opposing wave energy at longer periods, and is emphasized by the low LPDF levels observed during the 1 January high-Hs event near $\mathrm{H} 2 \mathrm{O}$ (Figure 7, model data, blue line). Another high-Hs event occurred on 5 February, with peak $\mathrm{Hs}$ north of $\mathrm{H} 2 \mathrm{O}$ in excess of $9 \mathrm{~m}$, while $\mathrm{Hs}$ at $\mathrm{H} 2 \mathrm{O}$ was less than $2.5 \mathrm{~m}$, and low $\mathrm{Hs}$ was 
Wave Model Hs \& Seismic Energy $[0.085,0.20] \mathrm{Hz}$

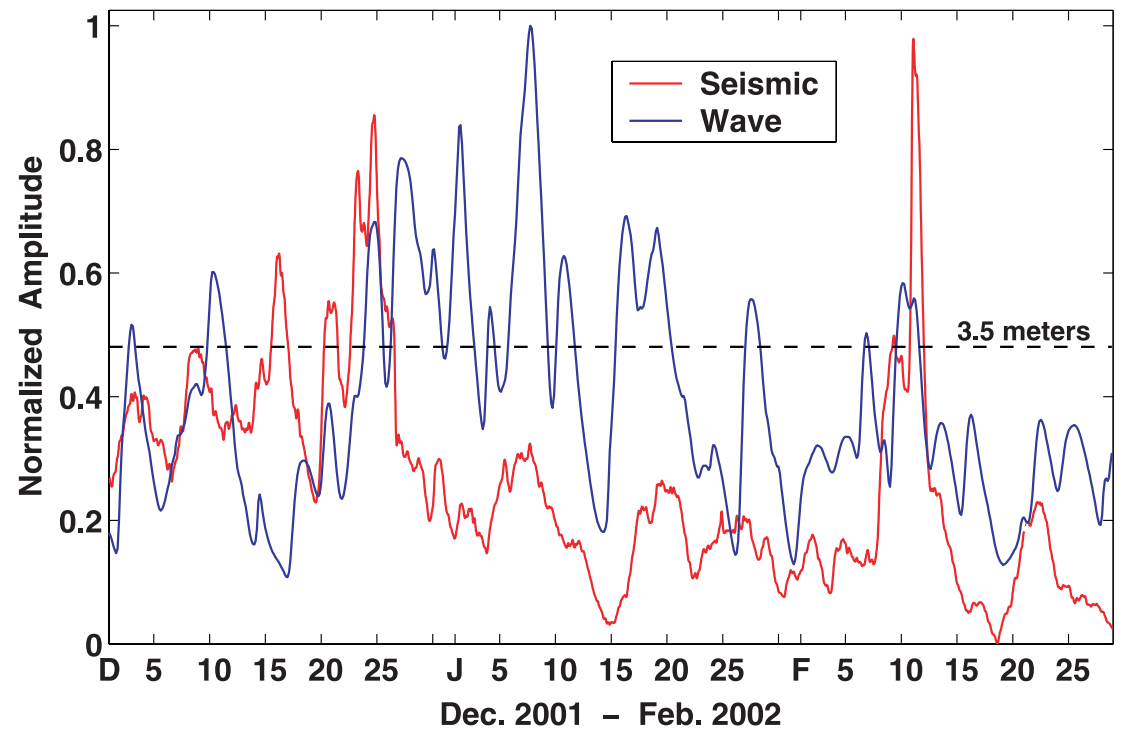

Figure 7. Normalized significant wave height $(\mathrm{Hs})$ model data at the nearest grid point to $\mathrm{H} 2 \mathrm{O}$, and $\mathrm{H} 2 \mathrm{O}$ RMS seismic energy in the $[0.085,0.20] \mathrm{Hz}$ band. Comparison confirms that high local swell amplitudes and high LPDF seismic levels at $\mathrm{H} 2 \mathrm{O}$ have a low correlation. The dashed line indicates the $3.5 \mathrm{~m}$ Hs level for reference.

observed at Hawaii and along the NE Pacific coastlines (see Animation 1). During this event, relatively low LPDF levels were observed at JCC, $\mathrm{H} 2 \mathrm{O}$, and KIP (difference spectrograms, Figure 9), consistent with little LPDF generation in the open ocean under individual storms.

[25] The highest swell observed during the JOIDES Resolution deployment over $\mathrm{H} 2 \mathrm{O}$ occurred near the end of 7 January, with a height of about $7 \mathrm{~m}$ and a period of $13 \mathrm{~s}$ (Figures 3 and 8 ). This swell may have contributed to the LPDF microseism levels near $0.14 \mathrm{~Hz}$ (Figure 6), but that cannot be established because microseisms generated at the West Coast were also arriving at this time, and LPDFs were also likely to have been generated at Hawaii during this wave event. Northeast swell from this event appears to initially have impacted the Hawaiian Chain, generating relatively high-amplitude LPDFs whose peak amplitude precedes that observed at the other stations (see Figure 6, KIP), underscoring the importance of the Hawaiian Islands as a source for LPDF energy in the North Pacific. Potentially, openocean wave-wave interactions between the postfrontal generated waves from the storm over $\mathrm{H} 2 \mathrm{O}$ and waves resulting from prefrontal winds from the cyclone centered northwest of Hawaii at about 8 January $00 \mathrm{hr}$ could also have contributed to the LPDFs observed.

[26] Peaks in LPDF energy occur on 14-16 December and 20 December (Figure 7), when low Hs was observed in the region near $\mathrm{H} 2 \mathrm{O}$ (see Animation 1). The 14-16 December LPDF peak appears to be associated with LPDF generation either from northeast swell arriving at the Hawaiian Islands or waves impacting the Vancouver Island coastline. High waves occurred at both the Aleutian Islands and along the California coast during 20 December, with the much closer California coast the likely source region for these signals.

[27] High-amplitude swell impacting the Aleutian Island chain must also generate LPDF microseisms, but their observation is less evident, most likely the result of the greater propagation distance to the stations studied, and coincident high wave activity at other locations throughout the NE Pacific basin producing LPDFs that mask Aleutiangenerated signals at $\mathrm{H} 2 \mathrm{O}$ and elsewhere. However, comparing relative levels at COLA and LLLB with $\mathrm{H} 2 \mathrm{O}$ suggests that the LPDF energy observed at $\mathrm{H} 2 \mathrm{O}$ and KIP on 24-25 December likely originates at the Aleutian Islands (compare Figure 6 with Animation 1). Additionally, Animation 1 indicates that the source area of the low-amplitude LPDF peak on 22 February (Figure 7) is most probably the Aleutian Islands.

[28] High-amplitude SPDF microseisms were observed at $\mathrm{H} 2 \mathrm{O}$ on 10 and 11 February 2002, extending to frequencies as low as $0.15 \mathrm{~Hz}$ (Figure 9). A strong cold front was passing $\mathrm{H} 2 \mathrm{O}$ at the time. The waves at $\mathrm{H} 2 \mathrm{O}$ reach a maximum 

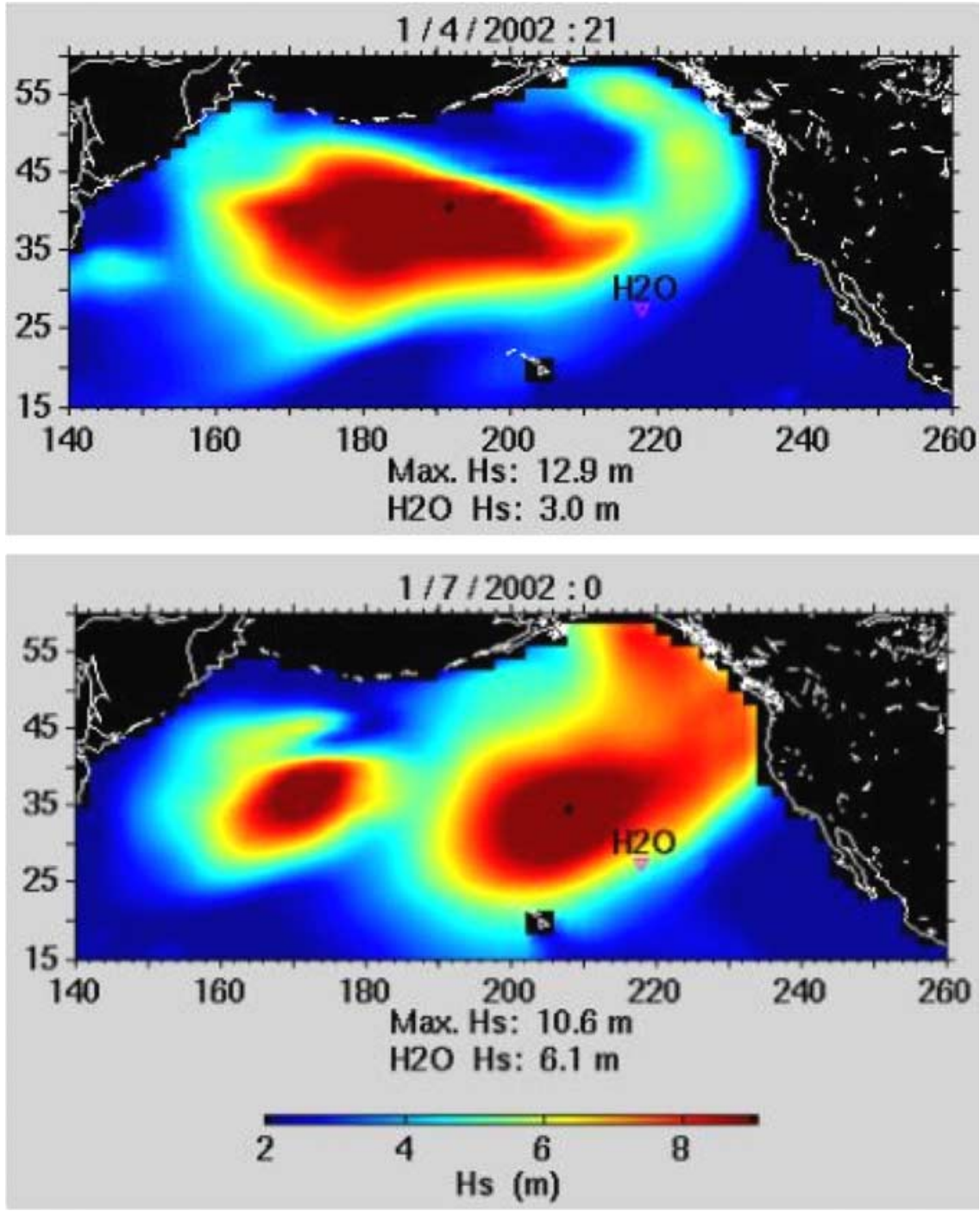

Figure 8. Snapshots of the wave model Hs during (top) the "quiet" LPDF period across the northeast Pacific during 1-4 January, when extreme Hs is observed over much of the basin but before waves from this storm reached the Pacific Northwest coast, and (bottom) the "noisy" period, when extreme waves from this event during 610 January were simultaneously impacting much of the Pacific Northwest coast and the Hawaiian Islands. (See Animation 1 for the wave climate over the North Pacific for the December 2001 through February 2002 period).

height of only $4 \mathrm{~m}$ during this period, but the SPDF microseisms reach the highest levels observed during the study period (Figure 13), extend to lower frequencies than usual, and also resulted in the highest LPDF levels observed because of the heightened levels above $0.15 \mathrm{~Hz}$ (Figures 7 and 13). The enhanced SPDF and LPDF microseisms are likely caused by the simultaneous occurrence of relatively long-period waves generated in opposite directions by the strong low-pressure region and the cold front (both relatively close to H2O), although some contribution from Hawaii generation to the observed levels cannot be ruled out. A similar situation may have occurred during 25 December when two storm systems near $\mathrm{H} 2 \mathrm{O}$ apparently forced opposing wave energy that resulted in relatively high LPDF levels between 0.15 and $0.20 \mathrm{~Hz}$ (Figures 6 and 7), although LPDF variability during this period is complicated by coastal wave activity.

[29] Note that the relative LPDF amplitudes at $\mathrm{H} 2 \mathrm{O}$ have a low correlation with model $\mathrm{Hs}$ at the nearest model grid point to $\mathrm{H} 2 \mathrm{O}$ for several events (Figure 7). In addition, comparison of Figure 7 with Animation 1 reveals that the two highest LPDF and SPDF peaks that occurred at $\mathrm{H} 2 \mathrm{O}$ (on 25 December and on 11 February) are not associ- 

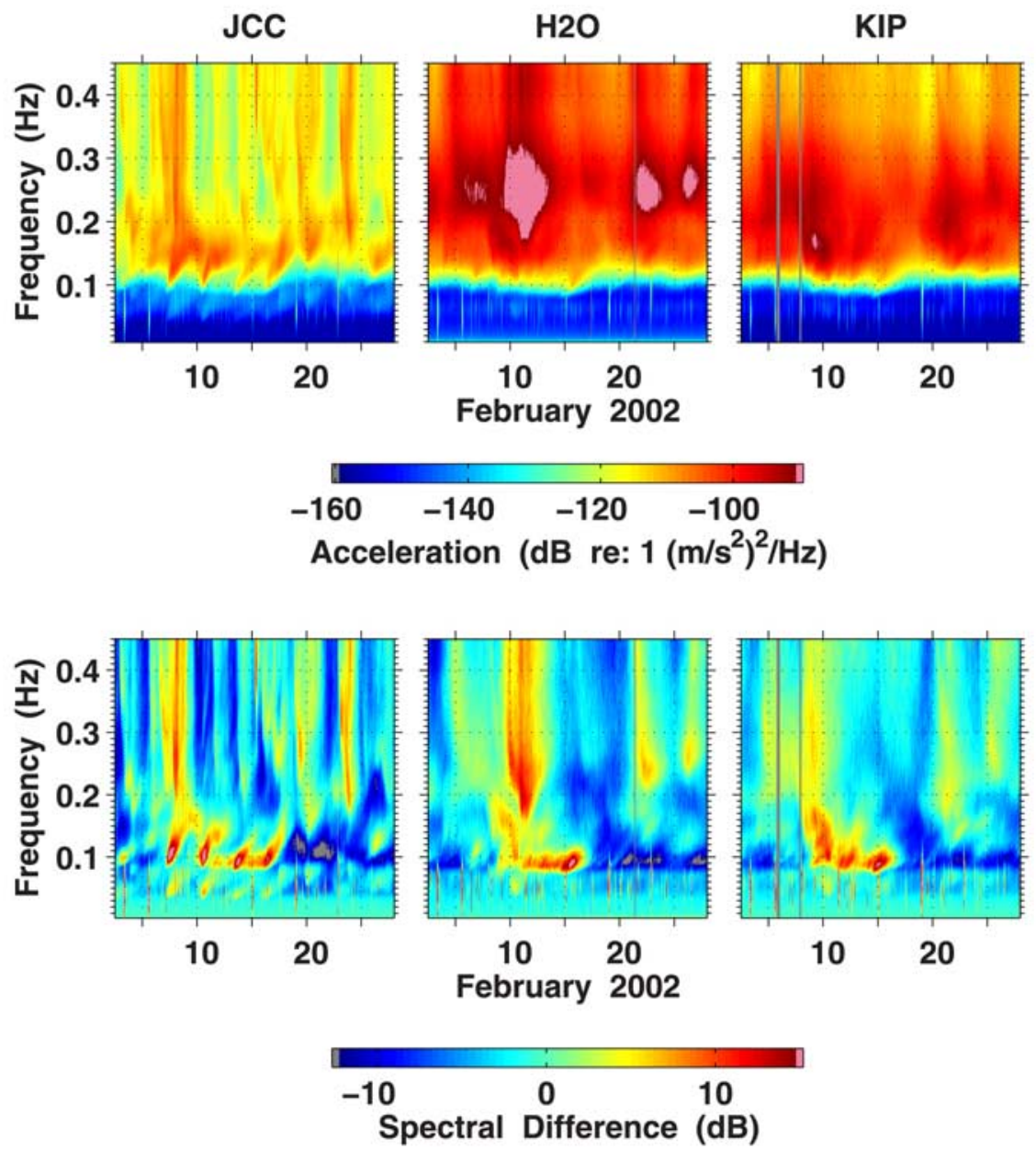

Figure 9. (top) Spectrograms and (bottom) difference spectrograms (obtained by subtracting the average spectrum in $\mathrm{dB}$ ) of vertical component seismic data at JCC, H2O, and KIP. Vertical stripes indicate times when data are missing. The spectral levels during 10-11 February are the highest levels observed at H2O during December 2001 to February 2002 in both SPDF and LPDF bands (see Figure 13).

ated with the highest Hs over $\mathrm{H} 2 \mathrm{O}$ during December 2001 to February 2002. It is important to note that elevated microseism levels on occasions such as these appear to result from the interaction of waves from concurrent multiple storm systems, producing high-energy microseisms at the upper end of the LPDF band, and can contribute significantly to the LPDF peaks observed. However, nearly all LPDF peaks occur when elevated wave activity is observed at Hawaii, the Aleutian Islands, or the West Coast.

\section{LPDF Propagation From Hawaii to California}

[30] An example of LPDF microseisms generated near Hawaii that were observed in California is shown in Figure 10. Spectrograms for the five-day period from 9-14 March 1993 are shown for four NOAA buoys and two seismic stations. Relatively high amplitude swell is recorded by buoys 51001 and 51026 (about $50 \mathrm{~km}$ northeast of Molokai, Hawaii) nearly coincidentally, indicating that the swell approached the Hawaiian chain from the northeast. Concurrently, high-amplitude LPDF microseisms are recorded at KIP at twice the wave frequency. A lower amplitude primary microseism peak is also seen at KIP at the same frequency as the waves, confirming Hawaii generation of respective associated DF microseisms. It is not clear that this wave event was observed at buoys 46006 and 46013 (see Figure 1 for locations), but it is clear that the microseisms recorded at KIP are observed concurrently at the NCEDC seismic station, BKS, at Berkeley, California, with a much lower amplitude signal than at KIP, strongly implying that the LPDF microseisms were generated 

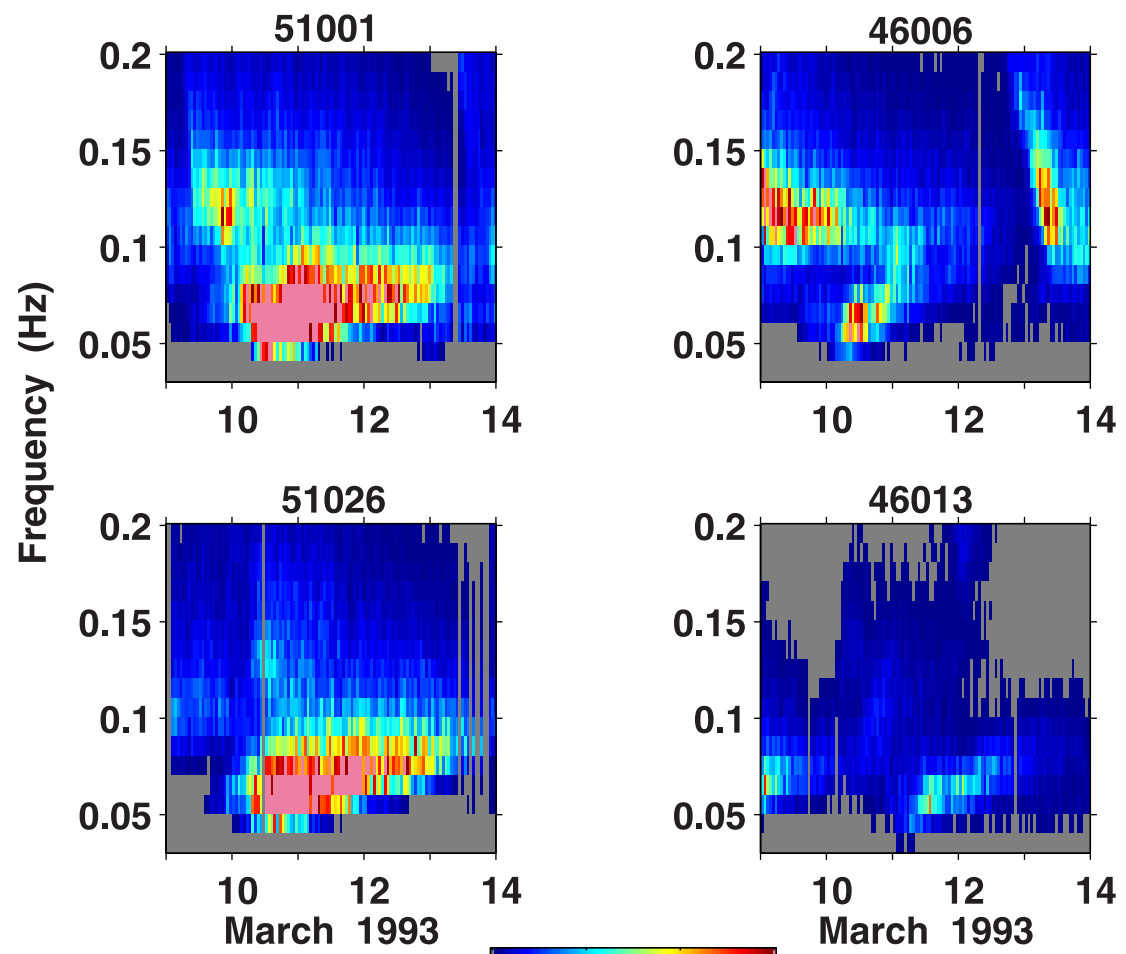

$\begin{array}{llll}0 & 5 & 10 & 15\end{array}$

Wave Spectral Density $\left(\mathrm{m}^{2} / \mathrm{Hz}\right)$
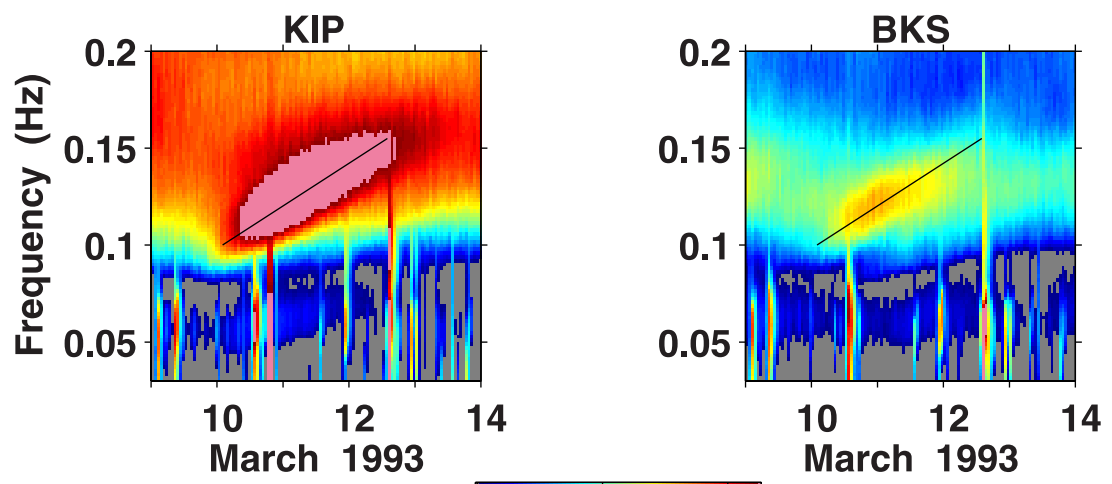

$-140-120-100$

Acceleration (dB re: $\left.1\left(\mathrm{~m} / \mathrm{s}^{2}\right)^{2} / \mathrm{Hz}\right)$

Figure 10. Spectrograms from 9-14 March 1993 of wave spectral density at NOAA buoys near Hawaii (51001 and 51026), in the open ocean (46006), and near San Francisco (46013), and seismic noise levels on Oahu (KIP) and at Berkeley, California (BKS). These data show LPDF microseisms generated at the Hawaiian Islands that were recorded at seismic stations in California. The locations of the [time, frequency] pairs used to generate the "slant" spectra shown in Figure 12 are indicated by thin black lines.

at Hawaii shorelines and traveled to California as Rayleigh waves. Note that the low wave heights along the California coast during this time period produced low-amplitude locally generated LPDFs that allowed detection of these Hawaii-generated LPDF signals, which would not have been the case for the 7-8 January 2002 event when regionally generated LPDFs along the U.S. West Coast would have masked similar telemicroseism signals.

[31] High-amplitude LPDF microseisms generated at the Hawaiian Islands that can be detected at the 
U.S. West Coast result from gravity waves approaching the Hawaiian chain from the northeast, illuminating the northeast coasts of all the Hawaiian Islands nearly simultaneously and thus providing reflected opposing wave energy at swell periods and a relatively large source area of wave-wave interactions. Gravity waves propagating sequentially down the axis of the Hawaiian Chain from the northwest generally illuminate a much smaller coastal area simultaneously, resulting in lower amplitude LPDF microseisms that are not observed at distance. Similarly, swell propagating down the West Coast, e.g., during 22 January, may illuminate relatively small coastal areas simultaneously compared to the January 6-10 event, and thus do not result in high LPDFs that can propagate to $\mathrm{H} 2 \mathrm{O}$ (compare Animation 1 with Figures 6 and 7). The approach angle of the gravity wave field in these instances may also be an important factor.

\section{Discussion}

[32] SPDF microseisms observed on land propagate to nearby seismic stations as Rayleigh waves, but are more quickly attenuated relative to longer period signals. SPDF and HOLU microseisms in the ocean extend to frequencies near $5 \mathrm{~Hz}$, while those observed on land usually have lower amplitudes at higher frequencies that drop below other noise sources near $2 \mathrm{~Hz}$. The gravity wave spectrum of swell from large storms has much more energy at longer periods, and long-period gravity waves reflect more efficiently off coasts [Elgar et al., 1994] to produce more opposing wave energy at long periods compared to short periods. Thus much more microseism energy in the LPDF band is generated near coastlines than in the deep ocean. This, combined with ocean stations being in the SPDF source region and higher attenuation of SPDF relative to LPDF microseism energy moving inland, results in a lower frequency microseism peak for inland seismic stations than for open ocean stations. Difference spectrograms from land seismic stations also show that there is often a clear break between SPDF and LPDF energy at about $0.20 \mathrm{~Hz}$ (Figure 6), with SPDF energy above $0.25 \mathrm{~Hz}$ correlating with local wind and wave conditions if the station is near a shoreline. If the station is near a shoreline where high-amplitude waves are impacting, the SPDF energy will extend to lower frequencies, merging with the LPDF energy. In this case, the local shoreline is the dominant source region for both LPDF and SPDF microseisms.
[33] An estimate of open-ocean SPDF microseism effective $Q$ that includes intrinsic and scattering losses can be made on the basis of the duration of elevated SPDF levels and storm propagation speeds, which range from 30 to $40 \mathrm{~km} / \mathrm{hr}$ for the fastest fronts, somewhat faster than short-period gravity waves. The duration that SPDF spectral levels at $\mathrm{H} 2 \mathrm{O}$ remain above background levels near $0.35 \mathrm{~Hz}$ for a local windseas event is about a day (Figures 2 and 5). We assume that the wave spectral energy distribution remains constant as a front approaches and recedes, continuously generating the same amplitude SPDF. There is about a $10 \mathrm{~dB}$ drop from the peak SPDF levels to background over about a 12 hour time span, during which the front could have propagated about $500 \mathrm{~km}$, giving an effective attenuation, $\alpha$, of about $0.02 \mathrm{~dB} / \mathrm{km}$. This is a lower $\alpha$ (upper Q) bound since slower moving fronts would give higher $\alpha$ estimates. The Rayleigh wave group velocity dispersion curve (Figure 11) (G. Laske, personal communication, 2005), for an isotropic PREM model overlain with oceanic crust and a $5.4 \mathrm{~km}$ water layer, indicates little velocity variation at DF microseism frequencies. Using an average Rayleigh wave group velocity, V, of $1.25 \mathrm{~km} / \mathrm{s}$ gives an effective $Q$ estimate of about 40 from $\mathrm{Q}=\pi \mathrm{f} / \alpha \mathrm{V}$ [Toksoz and Johnston, 1981] at a frequency, $\mathrm{f}$, of $0.30 \mathrm{~Hz}$, assuming plane wave propagation. This low Q estimate is consistent with poor propagation of SPDF signals.

[34] The duration of elevated SPDF levels at JCC and LLLB is generally less than at $\mathrm{H} 2 \mathrm{O}$ and KIP (Figure 6), likely resulting from the lack of SPDF generation from receding storms as they move onto the mainland, unlike the open-ocean condition. Note that the break between SPDF and LPDF bands is less distinct at JCC and the other land stations, and generally extends to lower frequencies, possibly due to more opposing wave energy available at these intermediate periods from shore reflection along continental coastlines.

[35] The spectral ratio method [Toksoz et al., 1979] applied to the March 1993 LPDF arrivals at KIP and BKS (Figure 10) gives an alternative attenuation (effective Q) estimate. The associated "slant" spectra (determined as the amplitudes of the DF microseisms associated with the dispersed swell arrivals along the thin slanted black lines in Figure 10) show a relatively uniform reduction of spectral levels across available frequencies (Figure 12a). The difference between these spec- 


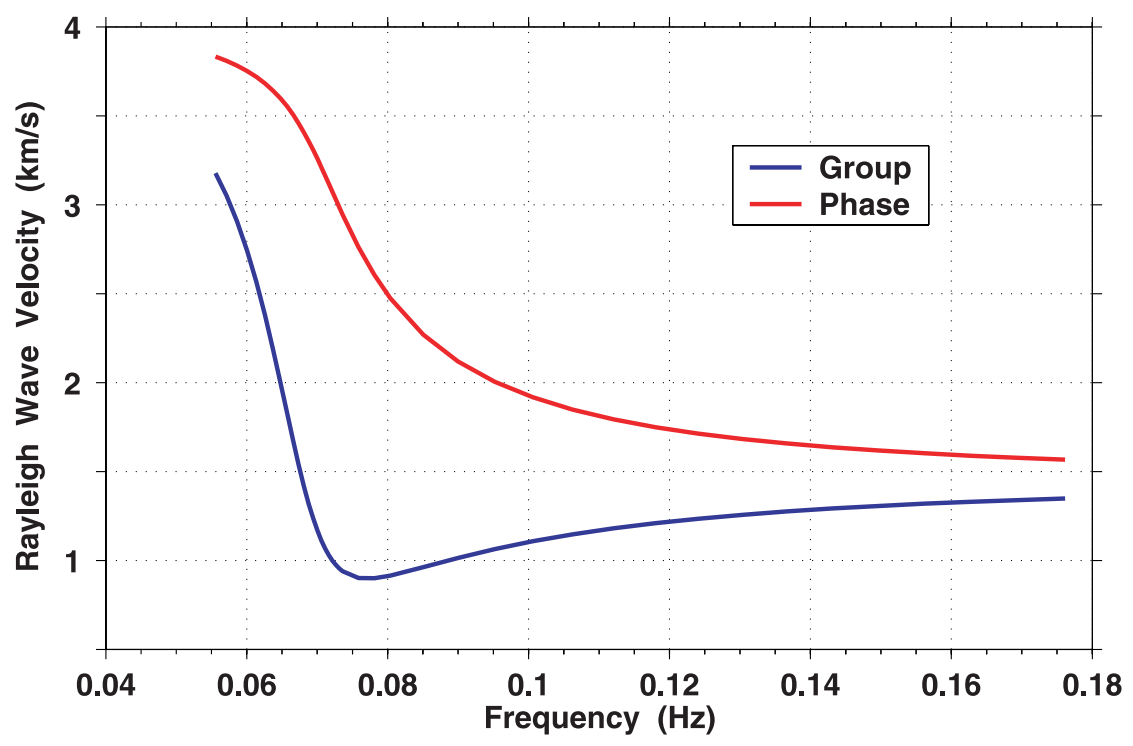

Figure 11. Rayleigh wave group and phase velocity dispersion curves for an isotropic PREM model overlain with oceanic crust and a $5.4 \mathrm{~km}$ water layer.

tra, scaled by the great circle distance between KIP and BKS, gives the attenuation, $\alpha$, in $\mathrm{dB} / \mathrm{km}$ (Figure 12b) as a function of frequency, $f$. Effective Q estimates (Figure 12c, solid black circles) at each $\alpha(f)$ and $\mathrm{V}(f)$ cluster near 55 and are reasonably consistent with the Q estimate determined above on the basis of storm propagation speeds and SPDF energy level drop-off. The least squares fit to these estimates (Figure 12c, red line) suggests higher $\mathrm{Q}$ at lower frequencies, suggesting either a strongly frequency-dependent $\mathrm{Q}$ in order to be consistent with the results of Canas and Mitchell [1978], who estimated Q above 250 for seismic surface waves below $0.05 \mathrm{~Hz}$ propagating across oceanic regions, or more substantial scattering losses for DF microseisms compared to earthquake-generated surface wave signals. The low DF microseism effective Q estimates obtained here are in general agreement with modal Q estimates by Schreiner and Dorman [1990], suggesting that most DF microseism energy is not coupled into the deeper crust and likely undergoes substantial losses from scattering in the upper crustal layers.

[36] The much higher SPDF levels at $\mathrm{H} 2 \mathrm{O}$ between 0.20 and $0.30 \mathrm{~Hz}$ compared to LPDF levels (Figure 9) indicate that relatively little LPDF energy is generated in the open ocean. Near-coastally generated LPDFs are observed at $\mathrm{H} 2 \mathrm{O}$, and can be observed to propagate from Hawaii to California only because much higher LPDF levels are generated in coastal locations as a result of the enhanced opposing wave components at longer periods from coastal reflection. Furthermore, the low Q estimates for both LPDF and SPDF microseisms indicate that, in general, little open-ocean generated microseism energy reaches continental stations. Thus wave statistics, obtained from inversion of DF microseism data recorded at nearcoastal land stations [Bromirski et al., 1999], will not be significantly biased by DF signals arriving from open ocean locations.

[37] The relative levels in the difference spectrograms shown in Figures 6 and 9 are somewhat misleading, as absolute SPDF levels are generally always high above $0.20 \mathrm{~Hz}$ at KIP, so small relative differences are generally observed above $0.20 \mathrm{~Hz}$ at KIP. The differences between nearcoastal land (JCC), mid-ocean seafloor (H2O), and island (KIP) stations are evident from comparisons of RMS spectral amplitudes at the three stations in the LPDF and SPDF bands (Figure 13). LPDF levels are generally somewhat higher at KIP than at $\mathrm{H} 2 \mathrm{O}$, consistent with KIP being near the source area for a portion of LPDF energy observed at $\mathrm{H} 2 \mathrm{O}$, with higher levels resulting at KIP because the Hawaiian Island coastlines provide more reflected/scattered opposing wave energy than is present at $\mathrm{H} 2 \mathrm{O}$. The LPDF peaks at $\mathrm{H} 2 \mathrm{O}$ on 25 December and 11 February appear to result in part from the extension of the SPDF band to lower frequencies during dual-storm open-ocean wave-wave interactions. On 11 February, neither JCC nor KIP exhibit corresponding peaks in SPDF energy to that observed at $\mathrm{H} 2 \mathrm{O}$, consistent with high 

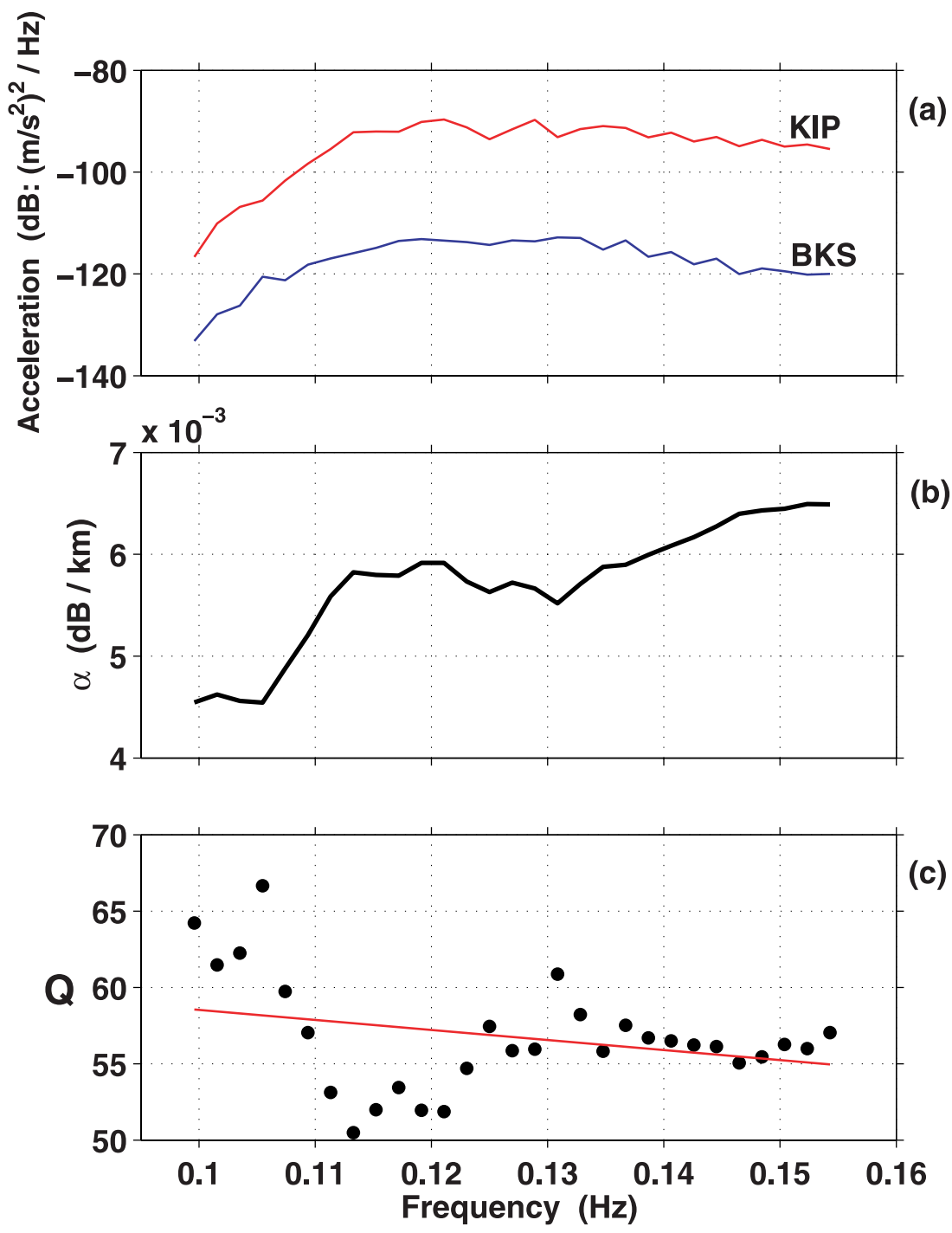

Figure 12. (a) "Slant" spectra of LPDF microseisms associated with dispersed swell arrivals at the Hawaiian Islands recorded at Oahu (KIP) and Berkeley, California (BKS) (see Figure 10). (b) The difference in spectral levels in $\mathrm{dB}$ between KIP and BKS scaled by the great circle distance between KIP and BKS, giving the attenuation, $\alpha$. (c) Effective oceanic DF microseism Q determined from $\alpha(f)$ estimates (middle) at Rayleigh wave group velocities $\mathrm{V}(f)$ from Figure 11. The least squares fit (red line) indicates decreasing $\mathrm{Q}$ with frequency.

attenuation of these signals. The much higher SPDF levels at $\mathrm{H} 2 \mathrm{O}$ are probably due in part to $\mathrm{H} 2 \mathrm{O}$ being nearer the dominant wave activity regions during this time period, as well as differences between seafloor and land-based sites. The lower LPDF and SPDF levels observed at JCC compared with the island and seafloor stations are consistent with the absence of sediment mode and interface wave DF energy that does not propagate well inland [Bromirski and Duennebier, 2002]. Note that LPDF levels at JCC and KIP are generally higher than their SPDF levels, while the opposite is almost always the case at $\mathrm{H} 2 \mathrm{O}$, indicative of differences between ocean bottom and land-based sites. Note also that the differences between SPDF and LPDF levels at land stations KIP and JCC are less than at mid-ocean bottom station $\mathrm{H} 2 \mathrm{O}$.

\section{Conclusions}

[38] Initial explanations of the "classic" LPDF spectral variation over time (low frequencies arriving first by hours) were attributed to swell from distant storms arriving above deep seafloor seismic 


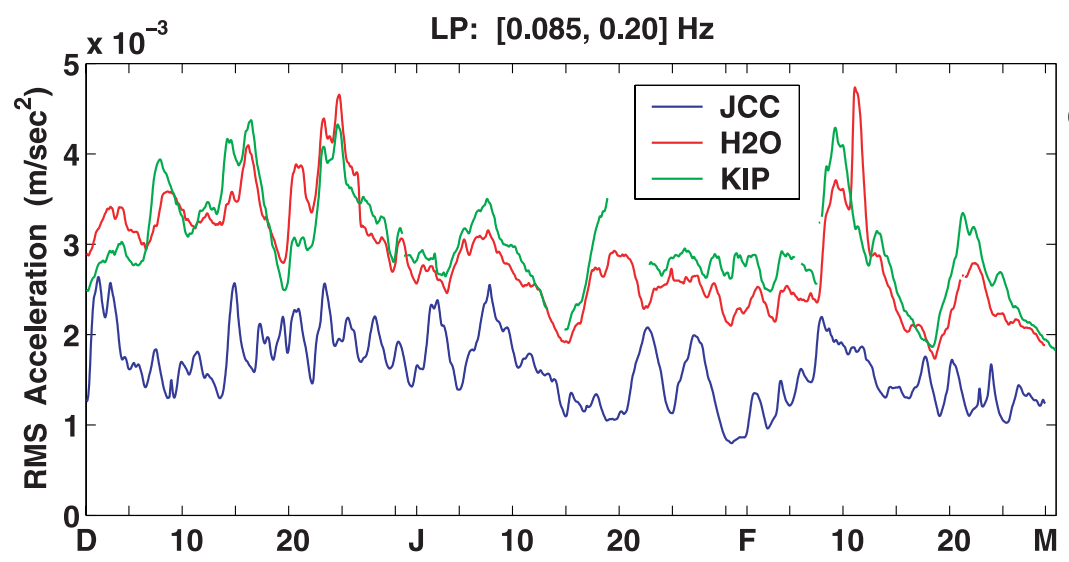

(a)

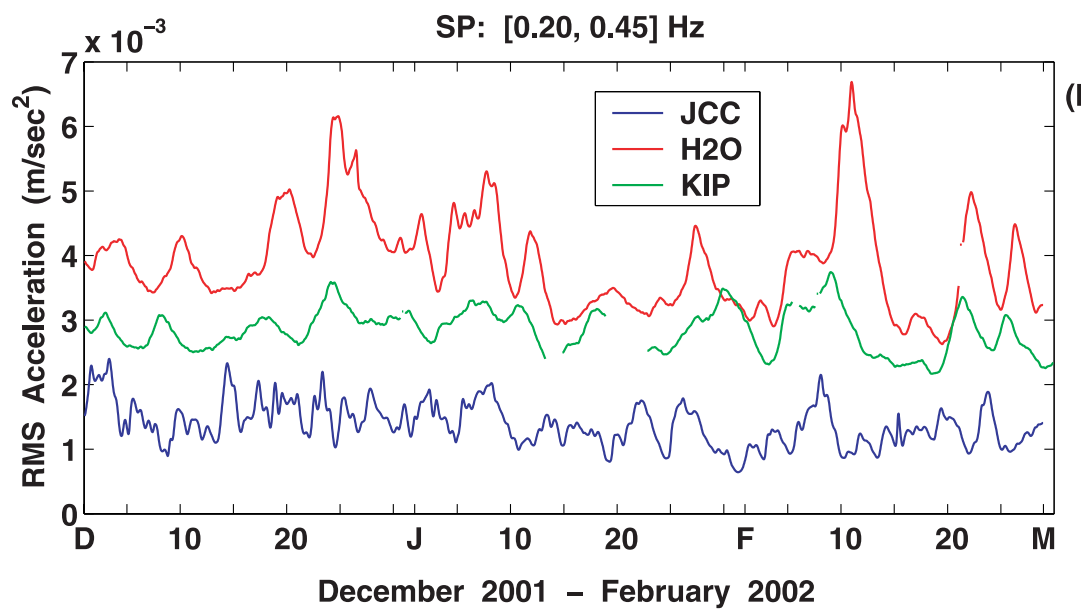

(b)

Figure 13. RMS levels of vertical component acceleration at near-coastal continental, JCC, mid-ocean seafloor, $\mathrm{H} 2 \mathrm{O}$, and mid-ocean island, KIP, seismic stations in the (a) LPDF $[0.085,0.20] \mathrm{Hz}$ and (b) SPDF [0.20, 0.45] Hz bands (see Figure 1 for locations).

stations and exciting LPFDs locally, even though swell from distant storms is unidirectional and thus the wave-wave interaction process would not be expected to occur. Our results indicate that much of the LPDF energy at frequencies less than $0.20 \mathrm{~Hz}$ is excited in near-coastal areas and propagates quickly as Rayleigh wave modes throughout the ocean basin. LPDFs are generated in the open ocean only when favorable weather conditions produce opposing swell. LPDF spectral variations over time for individual events necessarily follow that of the principal gravity wave field; e.g., if the wave train is dispersed, then the LPDFs will show similar variation. When LPDFs are generated at coastlines by swell from distant storms, the dispersion of the incident swell appears in the propagating LPDF energy, with elevated levels initially at lower frequencies. Most prior seafloor broadband seismic measurements were made in deep water relatively near coastlines (e.g., the OSNPE site) and the LPDFs detected were most likely dominated by generation at nearby shorelines.

\subsection{LPDF}

[39] We generally do not observe LPDF microseisms generated by gravity waves under individual storms at sea until waves from those storms impact shorelines. If the waves have high amplitudes and impact the shoreline over a wide area, the LPDF microseisms will likely be recorded over a large region in the frequency band from 0.08 to $0.20 \mathrm{~Hz}$. These microseisms are likely generated by the double-frequency microseism mechanism, interactions of $25-12 \mathrm{~s}$ period $(0.04$ to $0.085 \mathrm{~Hz})$ incident waves with opposing components reflected or scattered from shorelines. The likelihood of wave-wave interactions in the open ocean increases as wave period decreases. 
[40] In the open ocean, significant opposing wave energy in the LP band appears to be much less common than in coastal regions, and, in fact, there is only one indication of local generation of LPDF microseisms at frequencies less than $0.20 \mathrm{~Hz}$ at $\mathrm{H} 2 \mathrm{O}$ during the Leg 200 operations. Local generation of microseisms at $\mathrm{H} 2 \mathrm{O}$ is observed at frequencies below $0.20 \mathrm{~Hz}$ only when two large storms occur nearly coincidentally relatively near the site. Comparison of LPDF levels at $\mathrm{H} 2 \mathrm{O}$ with the wave model Hs animation suggests that the occurrence of two nearby cyclones in the open ocean produced opposing wave energy at periods greater than $10 \mathrm{~s}$.

[41] High-amplitude LPDF microseisms in the $[0.085,0.20] \mathrm{Hz}$ band generated along the West Coast of North America that can be observed at $\mathrm{H} 2 \mathrm{O}$ and Hawaii (KIP) occur only when long stretches of the West Coast are illuminated nearly simultaneously by portions of the same gravity wave field. This condition requires a large storm over the eastern North Pacific.

[42] Modeling of the ocean wave climate for the period studied allows us to locate the likely source areas for the LPDF microseisms observed.

\subsection{SPDF}

[43] Local wave-wave interaction causes high DF microseism noise levels at frequencies above about $0.20 \mathrm{~Hz}$ at open-ocean seismic stations. The highest DF microseism levels at $\mathrm{H} 2 \mathrm{O}$ occur in the band from 0.20 to $0.30 \mathrm{~Hz}$, as compared with the highest DF levels at continental sites that are below $0.20 \mathrm{~Hz}$. Peaks in SPDF energy at $\mathrm{H} 2 \mathrm{O}$ are well correlated with elevated wave heights above or near $\mathrm{H} 2 \mathrm{O}$. The close association of this energy with local wind variability indicates that energy above $0.30 \mathrm{~Hz}$ does not propagate laterally along the ocean floor for distances greater than a few hundred $\mathrm{km}$. Nearshore, SPDF microseisms generated by local wave activity propagate inland as Rayleigh waves where they are detected by nearby seismic stations. Attenuation of these ocean-generated seismic surface waves leads to lower SPDF noise levels on land stations relative to open-ocean stations, which are always in the SPDF source region.

\section{Acknowledgments}

[44] The facilities of the IRIS Data Management System, and specifically the IRIS Data Management Center, and the Northern California Earthquake Data Center, were used for access to waveform and metadata required in this study. The IRIS DMS is funded through the National Science Foundation and specifically the GEO Directorate through the Instrumentation and Facilities Program of the National Science Foundation under Cooperative Agreement EAR-0004370. Data from the NOAA weather buoys was obtained online from the NOAA National Buoy Data Center. The easy availability of these data is greatly appreciated. We thank Nick Graham at SIO for providing the wave model hindcast Hs data used to produce Animation 1. The cooperation of the JOIDES Resolution marine officers and crew on ODP Leg 200 in obtaining the environmental measurements is greatly appreciated. ODP is sponsored by the U.S. National Science Foundation and participating countries under management by Joint Oceanographic Institutions, Inc. This work was supported by the U.S. Science Support Program (User Reference: 418920-BA372; Task Order F001602) associated with the Ocean Drilling Program and is sponsored by the National Science Foundation and the Joint Oceanographic Institutions, Inc. Additional support was provided by the California Energy Commission and the California Department of Boating and Waterways as part of their program to improve boating facilities, access, safety, and education. Any opinions, findings and conclusions, or recommendations expressed in this publication are those of the author(s) and do not necessarily reflect the views of the National Science Foundation, the Joint Oceanographic Institutions, Inc., Texas A\&M University, the Texas A\&M Research Foundation, or the State of California. Support for Ralph Stephen was also provided by the National Science Foundation under grant OCE-0424633.

\section{References}

Babcock, J., B. Kirkendall, and J. Orcutt (1994), Relationship between ocean bottom noise and the environment, Bull. Seismol. Soc. Am., 84, 1991-2007.

Bradley, C. R., R. A. Stephen, L. M. Dorman, and J. A. Orcutt (1997), Very low frequency $(0.2-10.0 \mathrm{~Hz})$ seismoacoustic noise below the seafloor, J. Geophys. Res., 102, 11,70311,718 .

Bromirski, P. D. (2001), Vibrations from the "Perfect Storm," Geochem. Geophys. Geosyst., 2(7), doi:10.1029/ $2000 \mathrm{GC} 000119$.

Bromirski, P. D., and F. K. Duennebier (2002), The near-coastal microseism spectrum: Spatial and temporal wave climate relationships, J. Geophys. Res., 107(B8), 2166, doi:10.1029/ 2001JB000265.

Bromirski, P. D., R. E. Flick, and N. Graham (1999), Ocean wave height determined from inland seismometer data: Implications for investigating wave climate changes in the NE Pacific, J. Geophys. Res., 104(C9), 20,753-20,766.

Canas, J. A., and B. J. Mitchell (1978), Lateral variation of surface-wave anelastic attenuation across the Pacific, Bull. Seismol. Soc. Am., 68, 1637-1650.

Cessaro, R. K. (1994), Sources of primary microseisms, Bull. Seismol. Soc. Am., 84, 142-156.

Dorman, L. M., A. E. Schreiner, and L. D. Bibee (1991), The effects of shear velocity structure on seafloor noise, in Shear Waves in Marine Sediments, edited by J. M. Hovem et al., pp. 239-245, Springer, New York.

Dorman, L. M., A. E. Schreiner, L. D. Bibee, and J. A. Hildebrand (1993), Deep-water seafloor array observations 
of seismo-acoustic noise in the eastern Pacific and comparisons with wind and swell, in Natural Physical Sources of Underwater Sound, edited by B. Kerman, pp. 165-174, Springer, New York.

Duennebier, F. K., D. W. Harris, J. Jolly, J. Babinec, D. Copson, and K. Stiffel (2002), The Hawaii-2 Observatory Seismic System, IEEE J. Oceanic Eng., 27(2), 212217.

Elgar, S., T. H. C. Herbers, and R. T. Guza (1994), Reflection of ocean surface gravity waves from a natural beach, J. Phys. Oceanogr., 24, 1503-1511.

Essen, H., F. Krüger, T. Dahm, and I. Grevemeyer (2003), On the generation of secondary microseisms observed in northern and central Europe, J. Geophys. Res., 108(B10), 2506, doi:10.1029/2002JB002338.

Friedrich, A., F. Krüger, and K. Klinge (1998), Oceangenerated microseismic noise located with the Gräfenberg array, J. Seismol., 2, 47-64.

Hasselmann, K. (1963), A statistical analysis of the generation of microseisms, Rev. Geophys., 1, 177-210.

Haubrich, R. A., and K. McCamy (1969), Microseisms: Coastal and pelagic sources, Rev. Geophys., 7, 539-571.

Kibblewhite, A. C., and K. C. Ewans (1985), Wave-wave interactions, microseisms, and infrasonic ambient noise in the ocean, J. Acoust. Soc. Am., 78, 981-994.

Kibblewhite, A. C., and C. Y. Wu (1991), The theoretical description of wave-wave interactions as a noise source in the ocean, J. Acoust. Soc. Am., 89, 2241-3352.

Kibblewhite, A. C., and C. Y. Wu (1993), An analysis of the ULF acoustic noise field in the ocean, in Natural Physical Sources of Underwater Sound, edited by B. Kerman, pp. 189-202, Springer, New York.
Longuet-Higgins, M. (1950), A theory of the origin of microseisms, Philos. Trans. R. Soc. London, Ser. A, 243, 2-36.

McCreery, C. S., F. K. Duennebier, and G. H. Sutton (1993), Correlation of deep ocean noise $(0.4-30 \mathrm{~Hz})$ with wind, and the Holu Spectrum-A worldwide constant, J. Acoust. Soc. Am., 5, 2639-2648.

Schreiner, M. A., and L. M. Dorman (1990), Coherence lengths of seafloor noise: Effect of ocean bottom structure, J. Acoust. Soc. Am., 88, 1503-1514.

Stephen, R. A., et al. (2003a), Proceedings of the Ocean Drilling Program, Initial Reports [CD-ROM], vol. 200, Ocean Drill. Program, College Station, Tex.

Stephen, R. A., F. N. Spiess, J. A. Collins, J. A. Hildebrand, J. A. Orcutt, K. R. Peal, F. L. Vernon, and F. B. Wooding (2003b), Ocean Seismic Network Pilot Experiment, Geochem. Geophys. Geosyst., 4(10), 1092, doi:10.1029/ $2002 \mathrm{GC} 000485$.

Sutton, G. H., and N. Barstow (1990), Ocean-bottom ultralowfrequency (ULF) seismoacoustic ambient noise: 0.002 to $0.4 \mathrm{~Hz}$, J. Acoust. Soc. Am., 87(5), 2005-2011.

Toksoz, M. N., and D. H. Johnston (1981), Seismic Wave Attenuation, Geophys. Reprint Ser, 2, 459 pp., Soc. of Explor. Geophys., Tulsa, Okla.

Toksoz, M. N., D. H. Johnston, and A. Timur (1979), Attenuation of seismic waves in dry and saturated rocks: 1. Laboratory measurements, Geophysics, 44, 681-690.

Tolman, H. L. (1999), User manual and system documentation of WAVEWATCH III, version 1.18, Ocean Model. Branch Contrib. 166, 111 pp., NOAA/NWS/NCEP, Silver Spring, Md.

Webb, S. (1998), Broadband seismology and noise under the ocean, Rev. Geophys., 36, 105-142. 